\title{
Contemporary Challenges in Business Process Modeling / Management
}

In the previous chapters we have considered the means for describing the sequence of activities executed in a process. In the course of digitalization, processes in an organization and, in particular across organizations, are becoming more complex. In order to describe them nonetheless in a transparent way, it is necessary to organize them as networks of processes, or as a hierarchy of subprocesses.

When processes are increasingly supported by IT, two major aspects of IT support seem to be crucial. One aspect concerns the support of the activities specific for a process, e.g., creating a purchase order. The corresponding software applications are specific for each process. Normally, activities in a process are implemented by functions of such applications or, the other way around, activities of a process represent functions of application systems.

The other aspect concerns the control of the allowed sequences of activities, which is managed by software solutions in the form of so-called workflow systems. This software for controlling the execution sequence of a process can be derived directly from the process model if the syntax and semantics of the modeling language are precisely defined. This is a very important aspect for the digitalization of processes.

In workflow systems functions of software applications which implement certain actions of a process are incorporated into the associated functions of the model. A more detailed discussion on the structure of business process implementations can found in Chapter 7.

In the following sections we describe how the different Business Process Modeling languages support the structuring of complex process systems and to what extent the derivation of digital workflow is supported. 


\subsection{Handling of Complex Processes}

In an organization, business processes are connected with each other either directly or indirectly. The sales process is connected with the order handling process, the order handling process initiates the delivery and invoice processes, and so on. A language for specifying process behaviors should also offer possibilities for structuring complex interconnected process systems. It should allow the representation of the environment of a considered process, which means it should be possible to illustrate the relationships to other processes. If we want to define the activity sequences of the order handling process, we must be able to include the relationships to the sales and shipment processes. The interfaces to these neighboring processes should include the methods for exchanging the data and switching the control flow between the processes. In this chapter we describe the various possibilities to structure complex processes in the modeling languages defined in the previous chapter.

\subsubsection{Structuring Complex Processes in Flowcharts}

The only way to structure complex processes in flowcharts is by means of predefined processes. Predefined processes are named processes which are defined elsewhere. The following figure shows an example for using predefined processes.

In Figure 4.1 the process on the left side uses the predefined process "do shipment". This process is shown on the right side of the figure.

In flowcharts the control flow switches from the process which initiates a predefined process to the predefined process itself. There is no standardized way to describe a process architecture providing an overview of which predefined processes exist and in which other processes they are used.

In flowcharts it is assumed that all processes share all data. Hence, it is not necessary to specify the data required by a predefined process explicitly. Due to this tight coupling of processes to predefined processes, flowcharts are not the ideal

Figure 4.1: Structuring complex processes using flowcharts

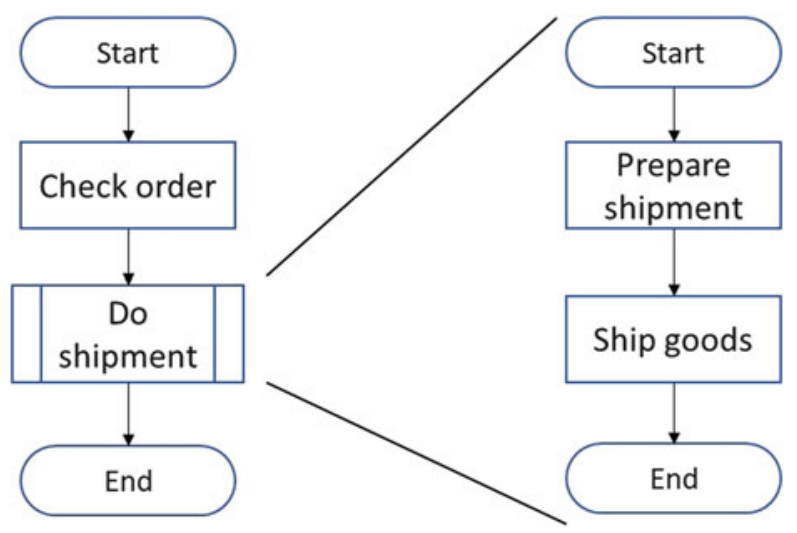




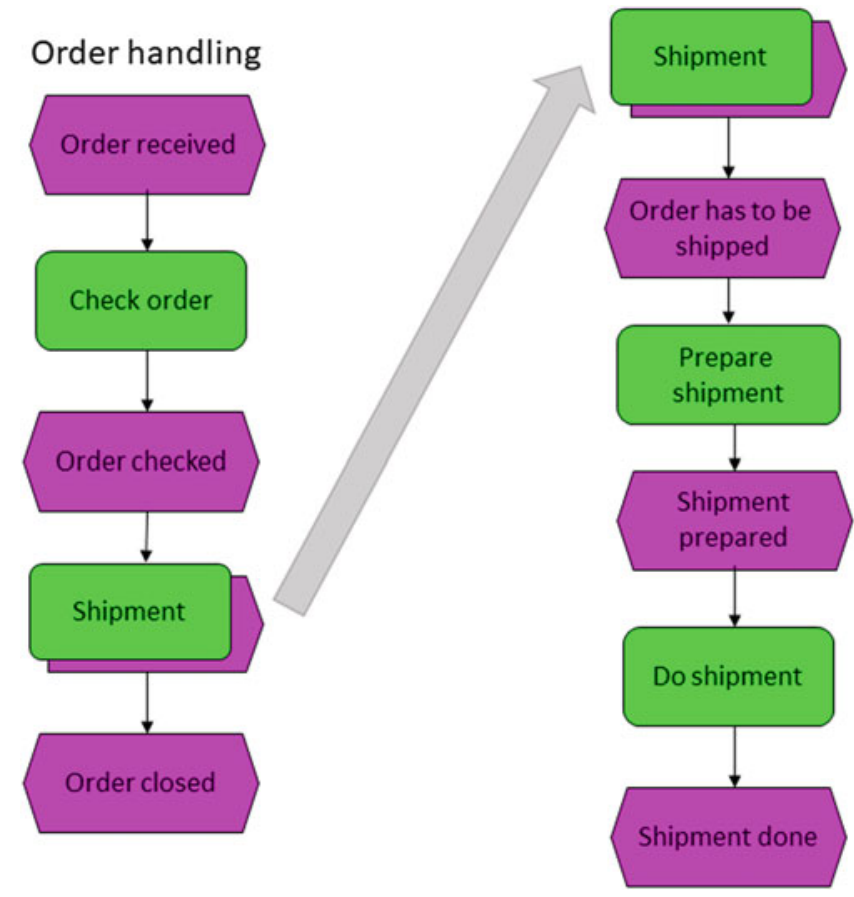

Figure 4.2: Structuring complex processes using EPCs

choice for loosely coupled organizations. In particular, in the case of cross-company processes, the ability to define where the process data is stored is essential.

\subsubsection{Structuring Complex Processes in Event-Driven Process Chains}

EPCs use subprocesses for structuring complex processes. The incorporation of subprocesses in EPCs is similar to predefined processes in flowcharts. Figure 4.2 shows the use of the interface symbol for integrating subprocesses.

The subprocess approach is not sufficiently expressive to describe complex process systems. Especially if it is necessary to describe the relations between various processes, the problems are the same as with flowcharts. Therefore, Value Chain Diagrams (VCD) have been introduced as an additional model type. VCDs allow describing which processes belong to a complex process system and how they are related to each other. Figure 4.3 shows that the process "order handling" starts the process "shipment".

In addition to this successor relationship, there is also the possibility to describe hierarchical relations. Figure 4.4 shows that the process system "order management" 
Figure 4.3: Order handling invokes Shipment
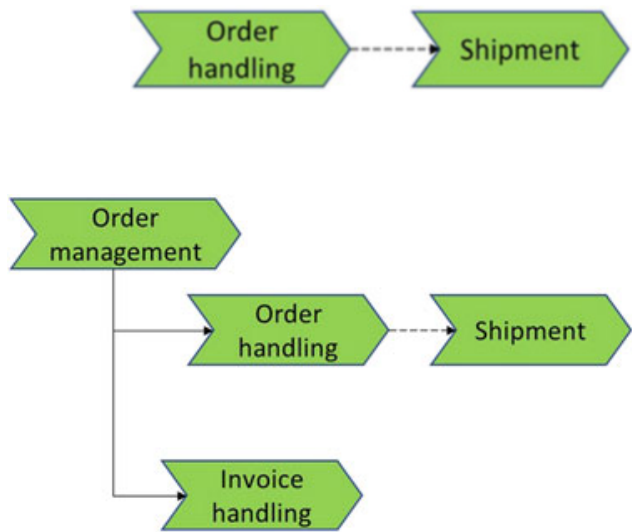

handling
Figure 4.4: Process hierarchy

consists of the process sequence "order handling" and "shipment", and the process "invoice handling".

\subsubsection{Structuring Complex Processes as UML Activity Diagrams}

UML activity diagrams do not contain a specific notational support for structuring complex processes. It is not allowed to use an activity diagram within another activity diagram (recursive use). The only possibility for structuring complex processes is to connect different activity diagrams by means of messages exchanged between them. However, there is no diagram type to specify a communication relationship between activity diagrams.

\subsubsection{Structuring Complex Processes in BPMN}

In BPMN the highest modeling level is represented by collaboration diagrams. If there are many involved parties in a process, and thus many pools with several swim lanes, then the 'big picture' of a process system may become quite difficult to understand. In order to overcome this problem, conversation diagrams have been introduced. Conversation diagrams represent an overview of a network of partners and how they communicate with each other. Figure 4.5 shows an example of a conversation diagram.

In this diagram a process system with the pools "order handling" and "shipment" is depicted. These pools communicate with each other via the message "start shipment". Conversation diagrams represent a top-level view of a BPMN collaboration diagram. Since nesting conversation diagrams is not allowed, the rectangle must be a pool and cannot consist of a conversation diagram on a lower level. Analogously to the predefined process concept in flowcharts or the subprocess 
Figure 4.5. Structuring complex processes using conversation diagrams

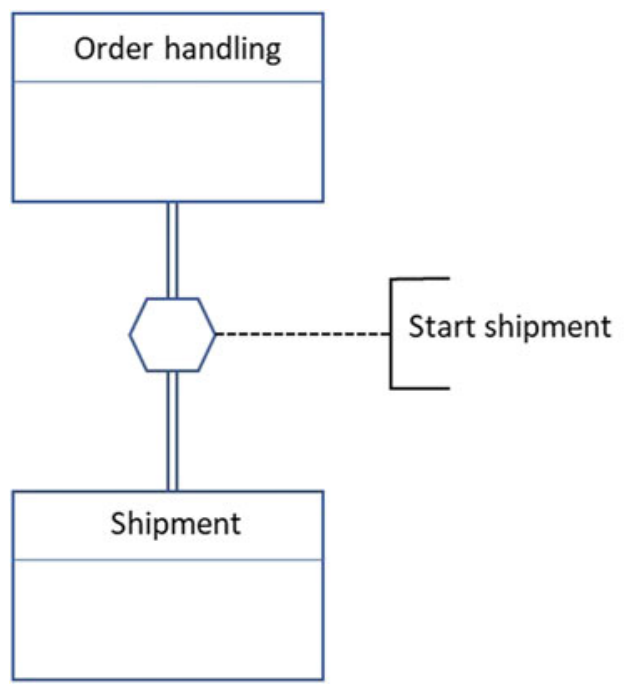

concept in EPCs, there is also a subprocess concept in BPMN. This concept has already been described in the previous chapter.

\subsubsection{Structuring of Complex Processes in S-BPM}

In Chapter 3 we introduced the modeling language S-BPM for representing subjectoriented business processes. S-BPM is based on the Parallel Activity Specification Scheme (PASS) [1]. PASS offers useful features for structuring complex process systems in a hierarchical way. Arbitrary levels of descriptions are allowed. We exemplify how levels of communication networks can be used to describe complex process systems with an example of a process for service provision in the case of a car accident service. This service (of an actual company) consists of several connected processes. It encompasses the main process for handling the car accident as well as supporting processes, e.g., for organizing towing and repair shop services, for handling insurance claims, for receiving and paying invoices, etc.

These processes are executed by various organizations, such as help desk service companies, towing service companies, car repair workshops, banks, etc. In most business process projects overall processes are not described completely in detail, but rather only in parts of a process. Which part of the process is represented in detail at a specific point in time depends on the perspective taken by the participants or departments involved in that part of the process. For instance, from the perspective of the help desk, only the help desk process needs to be considered in detail. However, we indeed have to take into account the environment in which a considered process is embedded. We must know which relations exist to other processes. It is necessary to know which inputs are required by neighboring processes and which 


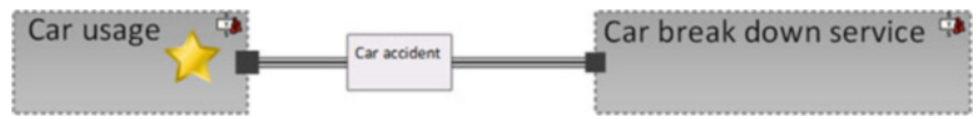

Figure 4.6: Highest process structure level of car accident service

results they deliver. A help desk process which organizes the towing services has to know how the towing service is requested and which further interactions are required. For example, it needs to be agreed whether the towing service, or rather the help desk, informs the client with respect to the arrival time of the tow truck.

\section{Process Architecture}

In the following we specify the required process architecture. In the diagrams, rectangles represent processes. Each process has a name. Processes consist of other processes and/or subjects. The lines between the rectangles represent the communication channels between processes. Each communication channel has a name and can contain other communication channels and/or messages.

Figure 4.6 shows the highest process level of the car accident service. In the "car usage" process the event "car accident" happens. In order to organize support an interaction is initiated with the process "car accident service". These processes exchange messages which are elements of the communication channel "car accident handling".

Figure 4.7 shows the next process structure level of the process "car accident service". In this level the process "car accident service" is decomposed into 10 processes. Eight of these processes, namely, the processes "incident management", "mobility service", "towing service", "insurance service", "car repair workshop", "banking", "payment handling" and "payment services" have a communication channel to the process "car usage". This means the communication channel "car accident handling" is separated into eight communication channels. Each of them covers the communication with the related process, e.g., the communication channel "accident notification" is the communication channel between the processes "car usage" and "incident management".

A process can also encompass other processes. This means that different levels of processes can be built. Figure 4.8 shows the next deeper level of our process hierarchy. The process "car repair workshop" is broken down into 6 processes. According to this separation the communication sets are also split, e.g., the communication set "handling repair service" is split into three parts, one part is handled by the process "service scheduling" the other by the process "car dropping" and the third by the process "customer satisfaction".

As already mentioned, processes cannot communicate directly with each other, but rather the active entities of a process, the subjects, communicate with each other. This means messages which are sent from one process to another process are received by a subject in that process. Messages belonging to a channel are assigned to respective sending or receiving subjects at the lowest level of a process architecture. This lowest level of a process description is the Subject Interaction Diagram 


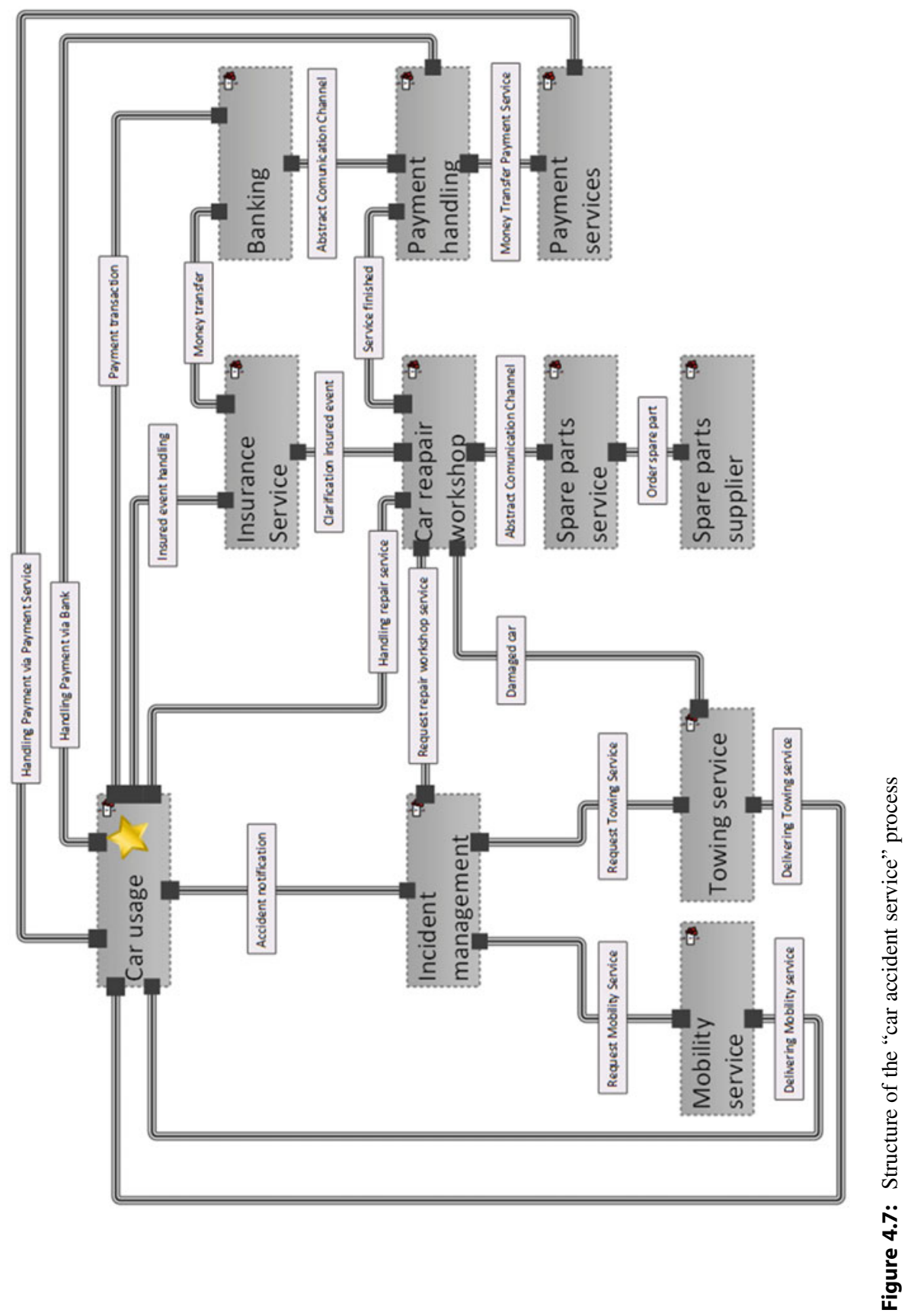




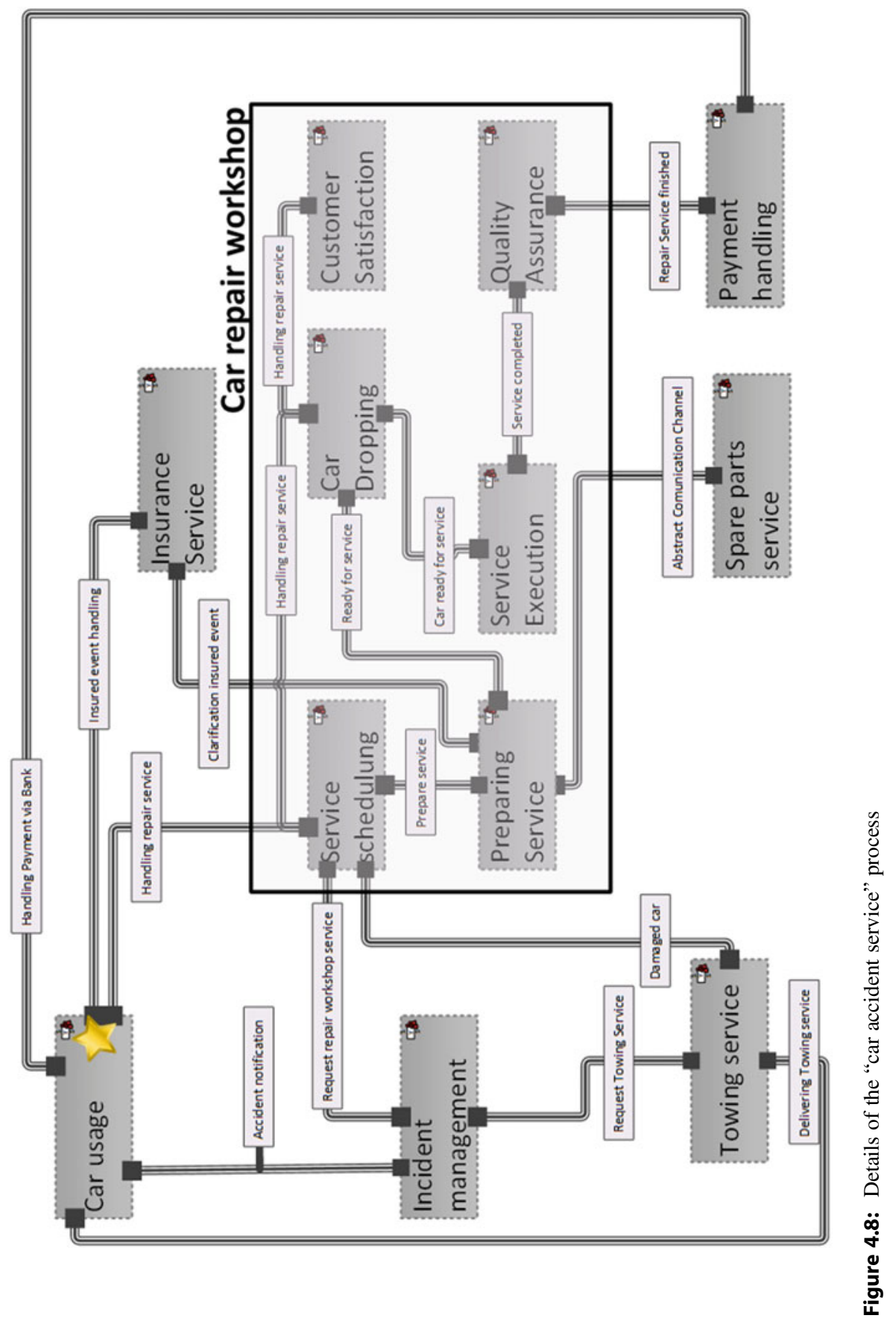




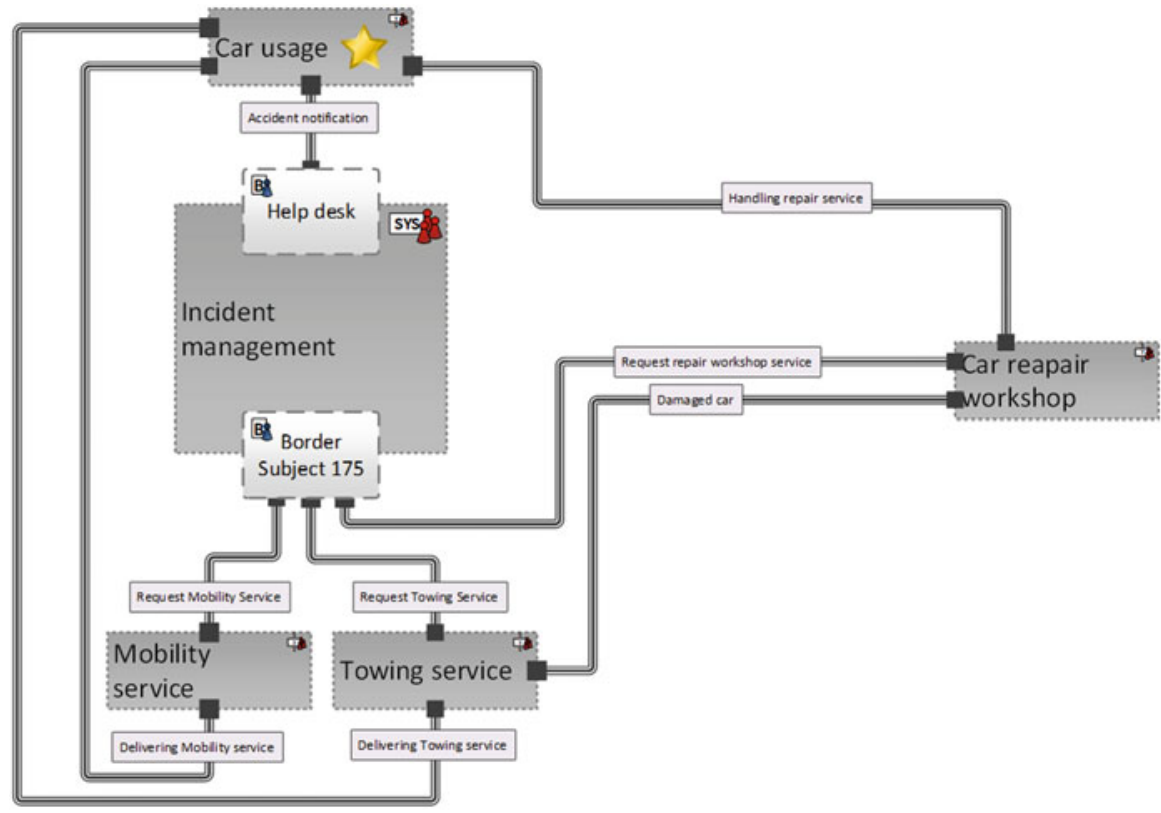

Figure 4.9: Interface (border) subjects of the "incident management" process

(SID) which shows the involved subjects of a process and the messages they exchange.

In the following we consider the process "incident management". This process does not contain other processes as in the case of the process "car repair workshop". The process "incident management" contains a SID. Some of the subjects of a process communicate with subjects of other processes. These subjects are called border subjects because they are at the border of a process to other processes. Figure 4.9 shows the process "incident management" with its border subjects. There is a border subject "help agent" which communicates with the processes "towing service", "mobility service", and "car repair workshop", or more precisely, it communicates with a respective subject in each one of these processes. Another border subject of the process "incident management" which is called "help desk" communicates with a subject in the process "car usage".

The border subjects of the process "incident management" must have corresponding border subjects in those processes with which it communicates. The border subject "help desk" communicates with the associated border subject of the process "car usage" and the border subject "help agent" communicates with the respective border subjects of the processes "car repair workshop", "towing service" and "mobility service". The process "incident management" with all of its border subjects is shown in Figure 4.10.

The border subjects of the processes "mobility Service", "towing Service", and "car repair workshop" have the same name "service agent" but are different subjects 


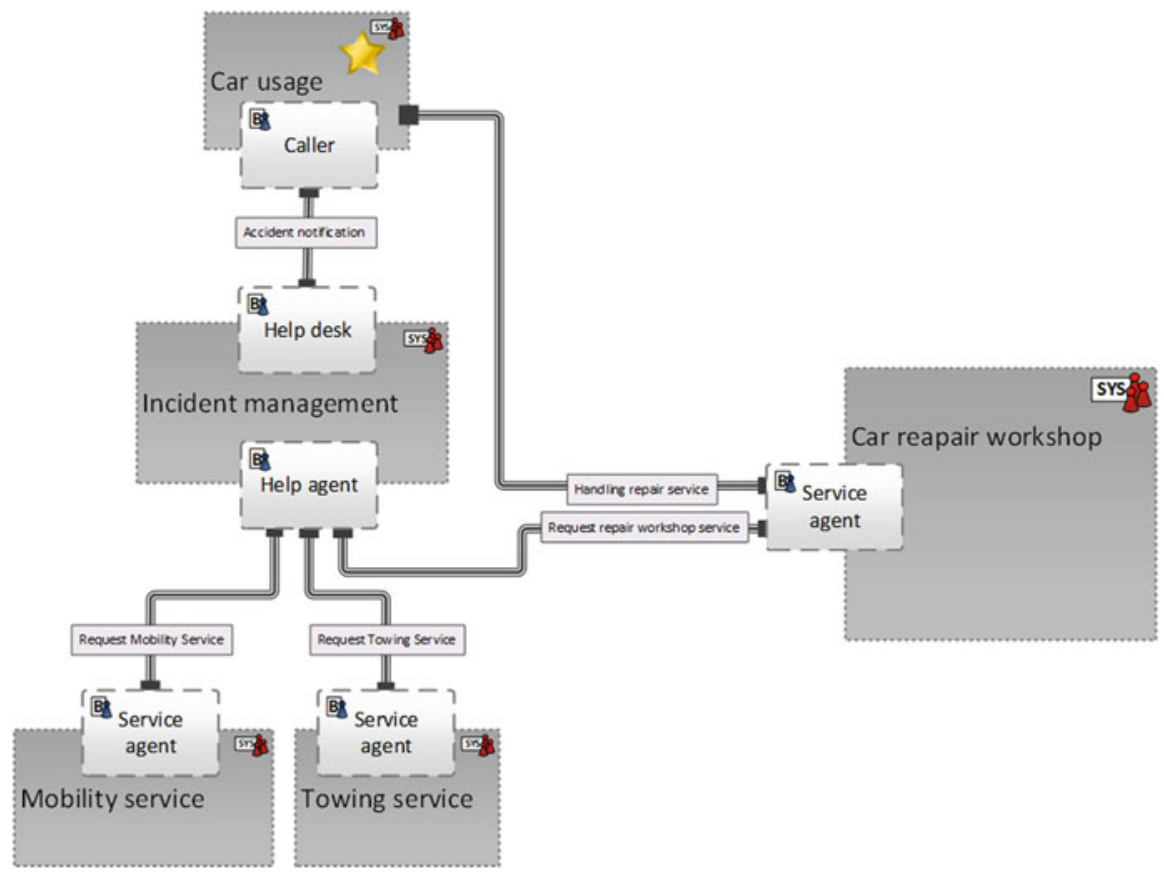

Figure 4.10: "Incident management" process with all border subjects

because they belong to different processes. Since the process "car repair workshop" consists of several layers, the corresponding border subject can belong to a process which is part of the process "car repair workshop" on a lower level.

From the perspective of the subjects inside the process "incident management", the border subjects of the processes "mobility service", towing service", and "car repair workshop" are interfaces to these processes, therefore they are called interface subjects in the (SID) Subject Interaction Diagram of a process. Figure 4.11 shows the SID of the process "incident management".

\section{Behavioral Interface}

Processes to which a considered process has communication relationships are called process neighbors, or just neighbors. Now we want to consider the details of the communication relationships between two neighbors. The interface between two processes is defined by the related border subjects and the allowed sequences in which the messages in a communication channel are exchanged between them [2]. As already described above, each message is defined by a name, and the data which are transported is the so-called payload.

A border subject observes the behavior of the border subject of the neighbor process and vice versa. Figure 4.12 shows the border subject "help desk" of the process "incident management" which communicates with the border subject "caller" of the process "car usage". Since we are considering the process "incident 


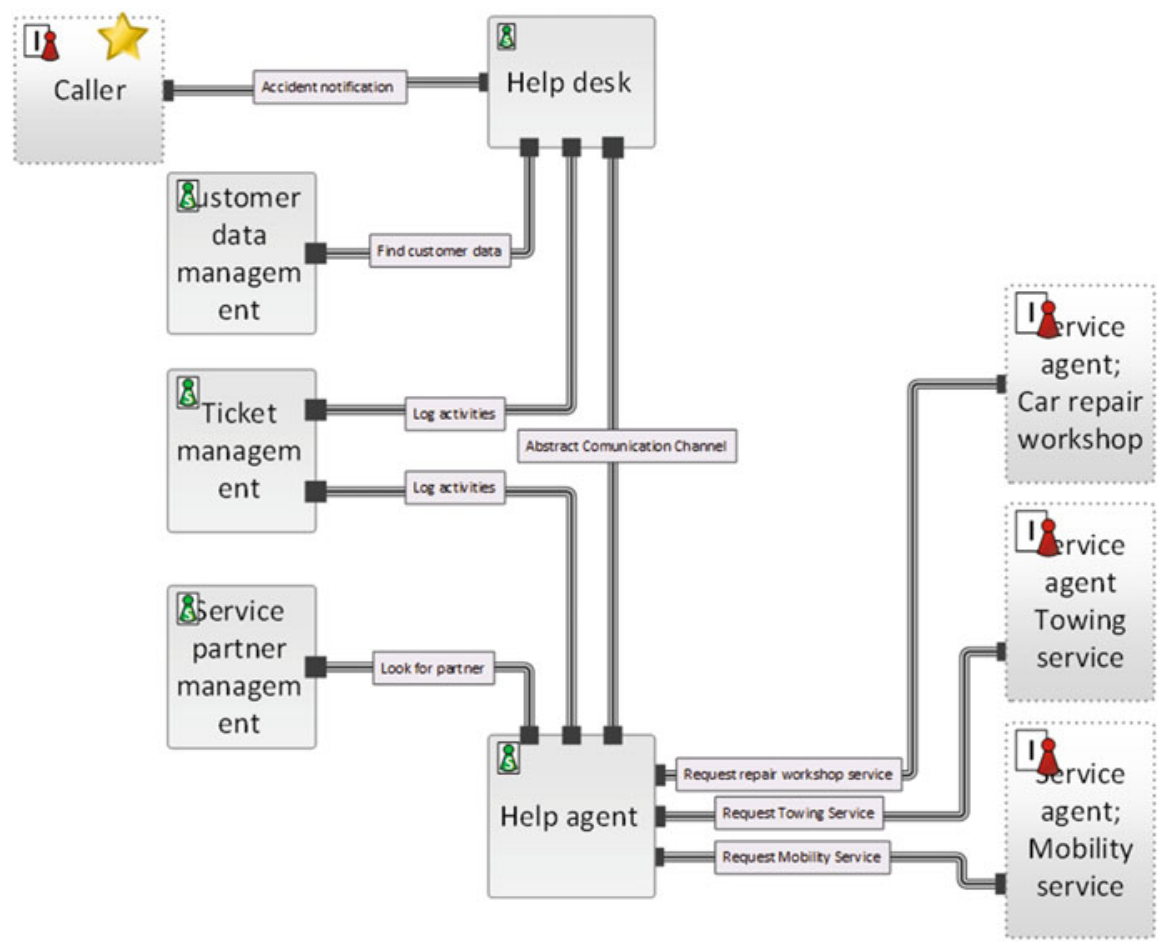

Figure 4.11: Subject Interaction Diagram of the "incident management" process

management", the border subject "caller" of the process "car usage" becomes an interface subject in the SID of the process "incident management".

Figure 4.13 shows the SID of the subject "help desk". Rather than specifying all of the channels, only the messages required for a towing service request are shown. A message "request towing service" stems from the interface subject "caller". This message is accepted by the subject "help desk". The subject "help desk" checks the customer data received with this message by sending a corresponding message "get customer data" to the subject "customer data management". This subject sends the complete customer data back to the subject "help desk" via the message "customer data". The subject "help desk" then checks the customer data. If the data are invalid a message "invalid customer data" is sent to the subject "caller" and the process is finished.

If the customer data are valid, the subject "help desk" creates a trouble ticket with this data which is sent to the subject "ticket management" via the message "store ticket". After that, the message "towing service requested" is sent to the "help agent" that organizes the towing service. The part of the communication structure of the subject "help agent" for organizing the towing service is not shown in Figure 4.13. We only see that the subject "help agent" sends the message "towing service ordered" to the subject "help desk". This message contains all the data about the 


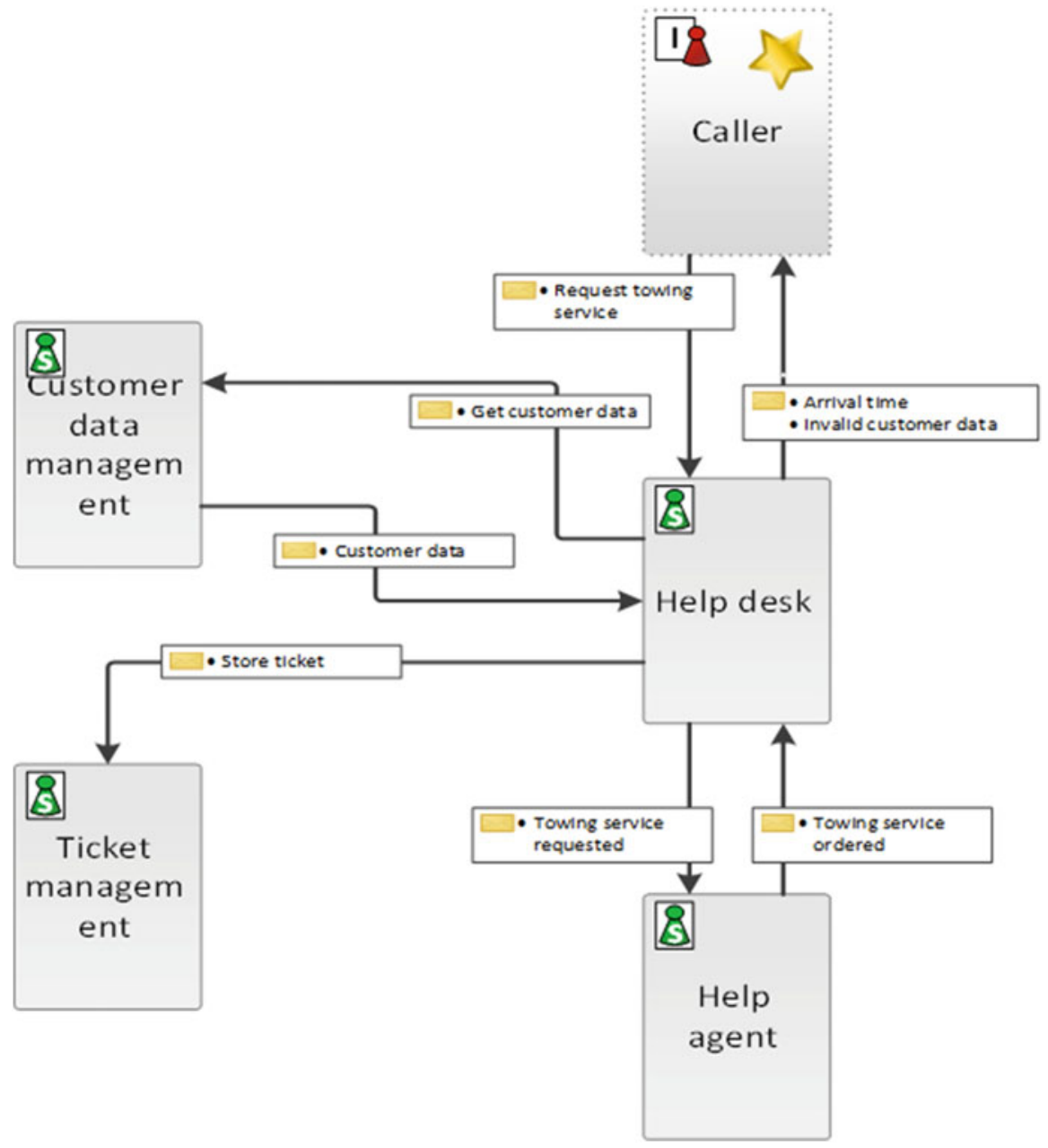

Figure 4.12: Subject interactions of the subject "help desk"

service, e.g., name of the towing company and arrival time. The subject "help desk" forwards this data to the interface subject "caller".

The behavior described in Figure 4.13 contains the communication of the subject "help desk" with all neighbor subjects, including the communication with the interface subject "caller". From the perspective of this subject, the communication of the subject "help desk" with its other neighbor subjects is not relevant. For the subject "caller" only the communication sequence between itself and the subject "help desk" is relevant. These allowed communication sequences are called the behavioral interface.

The behavioral interface between two subjects can be derived from the complete behavior of one of these subjects by deleting the interactions with all the other 
Figure 4.13: Part of the behavior diagram of the subject "help desk"

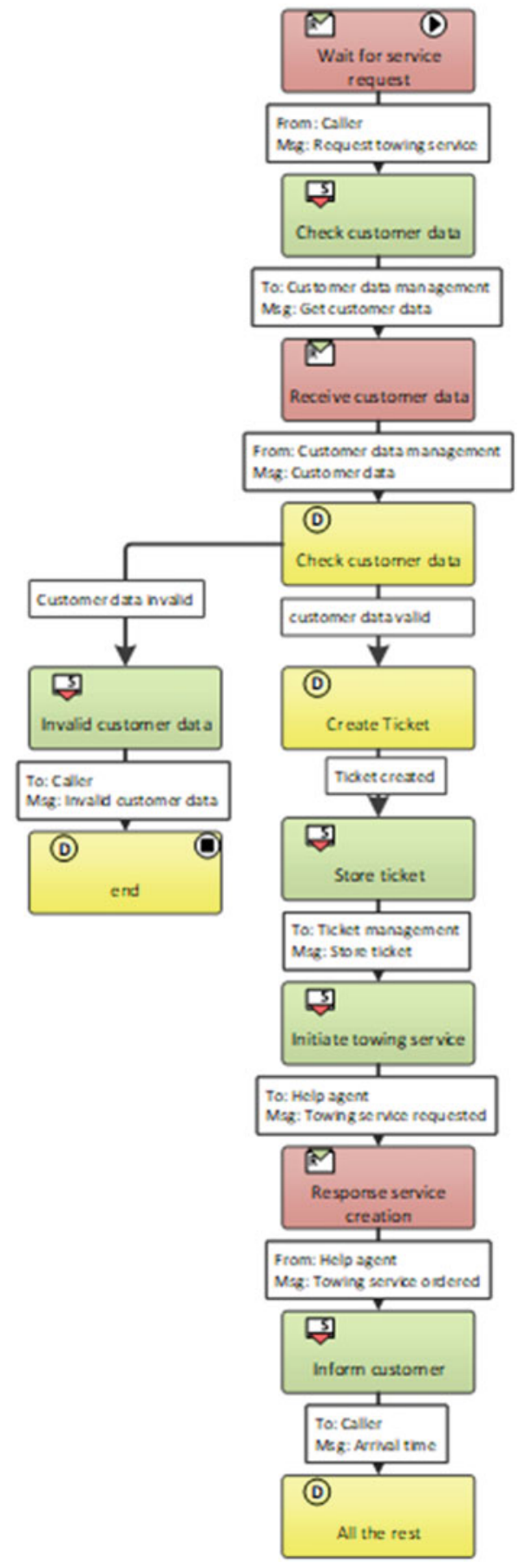




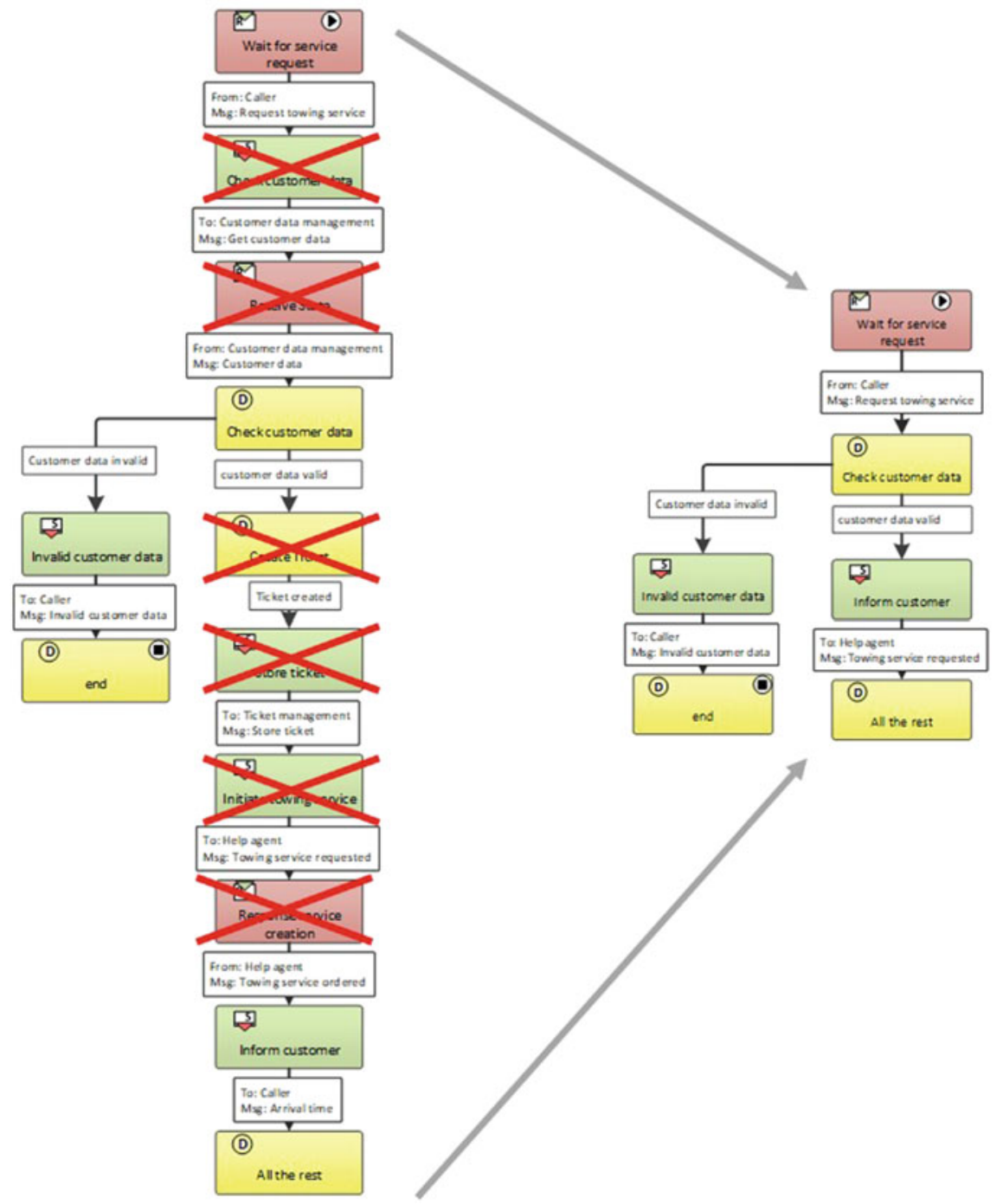

Figure 4.14. Sample behavioral interface

subjects [3]. Figure 4.14 shows how the communication sequence relevant for the communication between the subjects "help desk" and "caller" is derived from the complete behavior of the subject "help desk". 


\subsection{Readiness for Digitalization}

In this section we investigate to what extent process models are specified in a precise syntactic and semantic notation in the different modeling languages to enable generation of digital workflow support automatically. Readiness for digitalization denotes the capability to support semantically rich process specifications in an accurate way, allowing for a corresponding automated execution of process models. We shed light from this perspective on some notational schemes before demonstrating for subject-oriented representations how behavior models could be handled from a well-defined semantic representation and processing perspective.

\subsubsection{Readiness for Digitalization of Flowcharts}

The standard for flowcharts does not contain precise syntax and semantic descriptions. Due to their long history and widespread use, the importance of flowcharts is more or less common knowledge. Flowcharts have no underlying data model to share data between various diagrammatic editing tools for flowcharts, databases or other programs, such as project management systems or spreadsheets. There exist many applications and visual programming languages that use flowcharts to represent and execute programs [4]. However, these tools focus on programming, and not on business processes.

\subsubsection{Readiness for Digitalization of Event-Driven Process Chains}

There are many tools for creating EPC-based process models. Up to now there is no standardized way for storing these models. This means models created, for example, with tool A cannot be used in tool B. The tool most commonly used for creating EPC-based process models is ARIS. ARIS uses its own data model. Hence, process descriptions produced with ARIS cannot be processed with another tool. There have been some research activities to define a general data model [5] and also some research projects with respect to the direct execution of EPC models [6]. In practice, however, only the ARIS tool suite is used for creating EPC specifications and the authors are not aware of any projects in which EPCs are executed directly.

\subsubsection{Readiness for Digitalization of UML Activity Diagrams}

There are many UML-based tools - a list of them can be found in Wikipedia [7] which support the creation of activity diagrams. The OMG XMI standard specifies a structure that uses XML for interchanging models between various tools. Although in principle, this standard allows the handling of process models with different tools, in practice the transformation of model descriptions between various tools can be cumbersome: Many tool manufacturers create variations of the standard in different 
ways, e.g., they do not support some notational elements or they add other notational elements.

Most UML tools support the generation of code for several target languages. A special code generation for activity diagrams has been proposed in existing research [8]. This code generation targets real time systems and it still needs to be investigated as to what extent it can be used for business processes. The authors could currently not find any UML-based tool suite which is recommended for implementing business processes.

\subsubsection{Readiness for Digitalization of BPMN}

The BPMN standard contains an XML data model which allows the processing of a process model by different tools. Since in practice each tool vendor places its focus on different aspects of BPMN and interprets the standard in a special way, the transfer of a process model from one tool to another can be tedious [9].

In the standard's documentation the execution semantics is described in natural language. At the Software Competence Center in Hagenberg, Austria a formal semantic for the process diagrams of BPMN has been defined [10]. For the formal description of the BPMN semantic, the Abstract State Machine formalism has been used $[11,12]$. In this project, several ambiguities, inconsistencies and gaps in BPMN have been identified [10].

There are many tools which also support the execution of BPMN processes. However, the majority of these tools do not fully implement the BPMN standard. Most tools support a limited set of execution elements and do not interpret them in fully compatible ways, leading to partially differing execution outcomes for identical process models [13].

\subsubsection{Readiness for Digitalization in Subject-Oriented Process Specifications}

For the S-BPM language, which is based on PASS [1], a standard ontology in OWL [14] has been defined [15]. This ontology allows a PASS specification to be processed with different tools, if these tools follow the standard ontology.

Each subject has a base behavior and may have additional subject behaviors for macros and guards. All these behaviors are subclasses of the class SubjectBehavior. The details of these behaviors are defined as state transition diagrams (PASS behavior diagrams). These behavior diagrams are represented in the ontology with the class BehaviorDescribingComponent (see Figure 4.15). The behavior diagrams have the relation "BelongsTo" to the class SubjectBehavior. The other classes are needed for embedding subjects into the Subject Interaction Diagram (SID) of a S-BPM model (see section 3.6).

The following figure shows the details of the class BehaviorDescribingComponent. This class has the subclasses State, Transition and TransitionCondition. The subclasses of the state represent the various types of states (class relations 025,014 und 024 in the 


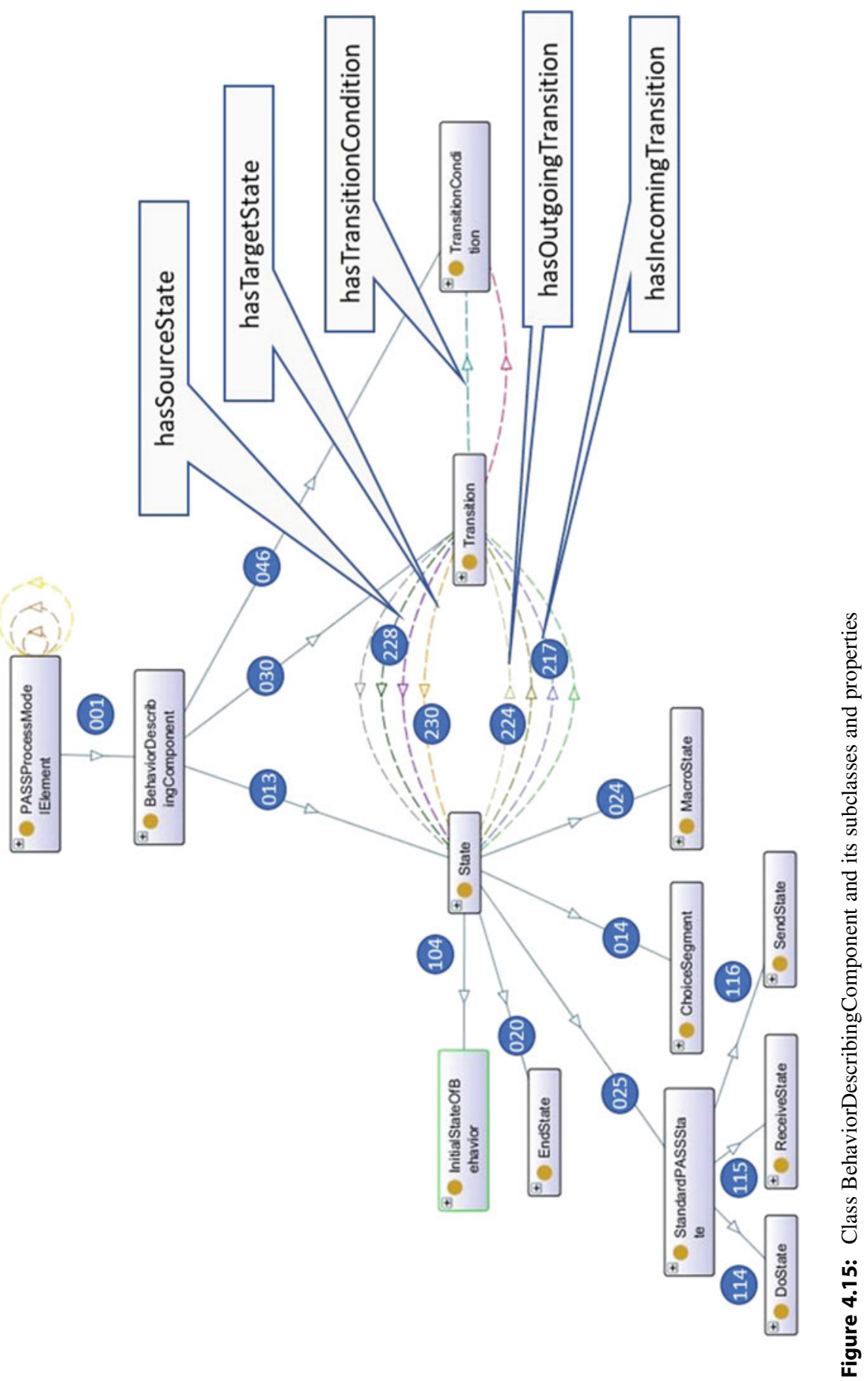




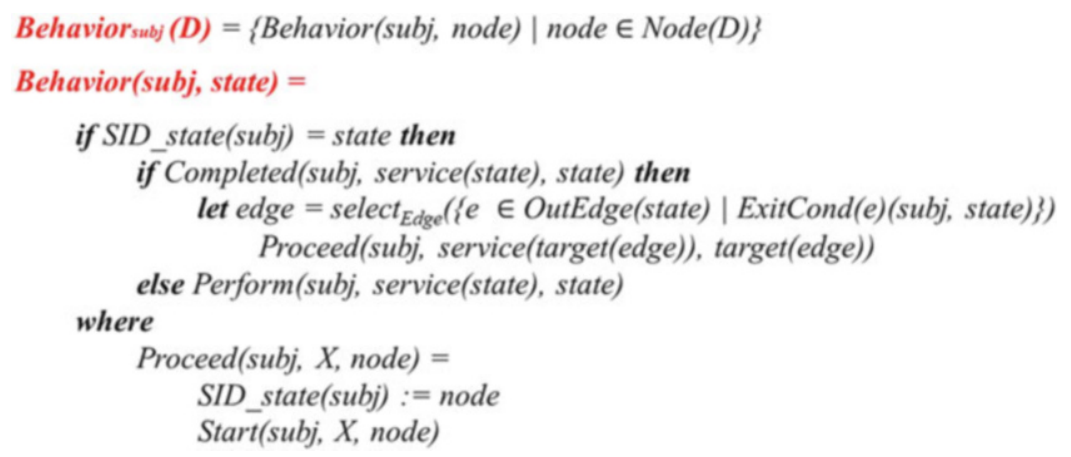

Figure 4.16: Main ASM functions of the interpreter

figure above). The standard states "DoState", "SendState" and "ReceiveState" are subclasses of the class "StandardPASSState" (subclass relations 114, 115 und 116). The subclass relations 104 and 020 allow a start state (class "InitialStatOfBehavior") and none or several end states (see subclass relation 020). The fact that there must be at least one start state and none or several end states is defined by so-called axioms which are not shown in the figure above.

States can be start and/or end points of transitions (see properties 228 and 230). This means a state may have outgoing and/or incoming transitions (see properties 224 and 217). Each transition is controlled by a transition condition which must be true before a behavior follows a transition from the source state to the target state.

The ontology defines only the structure of a process description. The dynamic aspect is not covered yet. The execution semantic of S-BPM models is described with Abstract State Machines (ASM) [16]. The ASM defines the algorithm of an interpreter that will "crawl" through a Subject Behavior Diagram (SBD) of a process model defined in the, not explicitly named, Subject-oriented Process Modeling language PASS as defined in the previous section 3.

Figure 4.16 shows the ASM-code for the interpretation of the behavior specification [17].

The behavior of a single subject subj is specified by the Behaviorsubj (D) rule, which takes the Subject Behavior Diagram $D$ as a parameter. From there on the Behavior(subj, node) rule defines how a single node behaves. As long as the service of that node is not completed the Perform rule will be called, which is refined for all given services $X$. Once the node is completed the outgoing transition will be determined by select $_{E d g e}$, the Proceed rule updates the current SID_state and initializes the new node with the Start rule, which also is refined for all services $X$.

The following table shows the relationship between the ASM interpreter specification and the classes and properties of the ontology.

The meaning of the colors is as following:

- OWL classes (brass coloured)

- Object properties (blue) 


\begin{tabular}{|c|c|c|}
\hline $\begin{array}{l}\text { Interpreter } \\
\text { Spec }\end{array}$ & Description & Corresponding OWL-Model Element \\
\hline SID_state & $\begin{array}{l}\text { Execution concept - no model rep- } \\
\text { resentation, not to be confused by } \\
\text { a model "state" in an SBD Diagram. } \\
\text { State in the SBD diagram define } \\
\text { possible SID States. }\end{array}$ & $\begin{array}{l}X \text { - Execution concept - the state the } \\
\text { subject is currently in as defined by } \\
\text { a State in the model }\end{array}$ \\
\hline$D$ & $\begin{array}{l}\text { A Diagram that is a completely con- } \\
\text { nected SBD }\end{array}$ & $\begin{array}{l}\text { SubjectBehavior - under the as- } \\
\text { sumption that it is complete and } \\
\text { sound. }\end{array}$ \\
\hline node & $\begin{array}{c}\text { A specific element of diagram D } \\
-\quad \text { Every node } 1: 1 \text { to state }\end{array}$ & State \\
\hline state & $\begin{array}{l}\text { The current active state of a dia- } \\
\text { gram determined by the nodes of } \\
\text { Diagram D }\end{array}$ & State \\
\hline initial state & \multirow{2}{*}{$\begin{array}{l}\text { The interpreter expects and SBD } \\
\text { Graph D to contain exactly one ini- } \\
\text { tial (start) state and at least one } \\
\text { end state }\end{array}$} & InitialStateOfBehavior \\
\hline end state & & EndState \\
\hline $\begin{array}{l}\text { edge / out- } \\
\text { Edge }\end{array}$ & $\begin{array}{l}\text { "Passive Element" of an edge in an } \\
\text { SBD-graph }\end{array}$ & Transition \\
\hline $\begin{array}{l}\text { ExitCondi- } \\
\text { tion }\end{array}$ & $\begin{array}{l}\text { Static Concept that represents a } \\
\text { Data condition }\end{array}$ & TransitionCondition \\
\hline subj & $\begin{array}{l}\text { Identifier for a specific Subject Car- } \\
\text { rier that may be responsible for } \\
\text { multiple Subjects }\end{array}$ & $\begin{array}{l}\text { Execution Concept - ID of a Subject } \\
\text { Carrier responsible possible multiple } \\
\text { Instances of according to specific } \\
\text { SubjectBehavior }\end{array}$ \\
\hline $\begin{array}{l}\text { Exter- } \\
\text { nalSubject }\end{array}$ & $\begin{array}{l}\text { A representation of a service exe- } \\
\text { cution entity outside of the bound- } \\
\text { aries of the interpreter } \\
\text { (The PASS-OWL Standardization } \\
\text { community decided on the new } \\
\text { Term of Interface Subject to re- } \\
\text { place the often-misleading older } \\
\text { term of External Subject) }\end{array}$ & $\begin{array}{l}\text { Represented in the model with In- } \\
\text { terfaceSubject }\end{array}$ \\
\hline $\begin{array}{l}\text { subject-SBD } \\
/ \\
S B D_{\text {subject }} \\
\end{array}$ & $\begin{array}{l}\text { Names for completely connected } \\
\text { graphs / diagrams representing } \\
\text { SBDs }\end{array}$ & $\begin{array}{l}\text { SubjectBehavior or rather Sub- } \\
\text { jectBaseBehavior as MacroBe- } \\
\text { haviors and GuardBehaviors }\end{array}$ \\
\hline $\begin{array}{l}\text { ser- } \\
\text { vice(state) / } \\
\text { ser- } \\
\text { vice(node) }\end{array}$ & $\begin{array}{l}\text { Rule/Function that reads/returns } \\
\text { the service of function of a given } \\
\text { state/node: }\end{array}$ & $\begin{array}{l}\text { Object Property: hasFunction- } \\
\text { Specification } \\
\text { (linking State, and Function- } \\
\text { Specification --> } \\
\text { (State hasFunctionSpecifica- } \\
\text { tion FunctionSpecification) }\end{array}$ \\
\hline
\end{tabular}




\begin{tabular}{|c|c|c|}
\hline $\begin{array}{l}\text { Interpreter } \\
\text { Spec }\end{array}$ & Description & Corresponding OWL-Model Element \\
\hline $\begin{array}{l}\text { function } \\
\text { state }\end{array}$ & \multirow[b]{3}{*}{$\begin{array}{l}\text { The ASM spec does not itself con- } \\
\text { tain these terms. The description } \\
\text { text, however, uses them to de- } \\
\text { scribe states with an according ser- } \\
\text { vice, e.g., a state in which a (Co- } \\
\text { mAct = Send) service is executed is } \\
\text { referred to as a send state } \\
\text { Seen from the other side: a Send- } \\
\text { State is a state with service(state) } \\
\text { = Send) } \\
\text { Both send and receive services are } \\
\text { a ComAct service. } \\
\text { The ComAct service is used to de- } \\
\text { fine common rules of these com- }\end{array}$} & DoState \\
\hline send state & & SendState \\
\hline receive state & & ReceiveState \\
\hline ComAct & $\begin{array}{l}\text { Specialized version of Perform-ASM } \\
\text { Rule for communication, either } \\
\text { send or receive. These rules distin- } \\
\text { guish internally between send and } \\
\text { receive. }\end{array}$ & $\begin{array}{l}\text { CommunicationActs with sub- } \\
\text { classes (ReceiveFunction } \\
\text { SendFunction) } \\
\text { DefaultFunctionReceive1_Envi- } \\
\text { ronmentChoice } \\
\text { DefaultFunctionReceive2_Au- } \\
\text { toReceiveEarliest } \\
\text { DefaultFunctionSend }\end{array}$ \\
\hline
\end{tabular}

The interpreter ASM Spec has the following main function or rules that are being executed while interpreted.

- BEHAVIOR(subj,state),

- PROCEED(subj,service(state),state),

- PERFORM(subj,service(state),state)

- $\operatorname{START}($ subj,X, node)

The following table shows the relationships between the ASM main functions and the classes of the OWL model elements. 


\begin{tabular}{|c|c|c|}
\hline Interpreter Spec & Description & $\begin{array}{l}\text { Corresponding OWL-Model Ele- } \\
\text { ment }\end{array}$ \\
\hline $\begin{array}{l}\text { BEHAV- } \\
\text { IOR(subj;state })\end{array}$ & $\begin{array}{l}\text { Main interpreter ASM- } \\
\text { rule/Method }\end{array}$ & Execution concept \\
\hline $\begin{array}{l}\text { BEHAV- } \\
\text { IOR(subj;node) }\end{array}$ & $\begin{array}{l}\text { ASM-Rule to interpret a specific } \\
\text { node of Diagram D for a specific } \\
\text { subject }\end{array}$ & Execution concept \\
\hline $\begin{array}{l}\text { Behaviorsubj } \\
\text { (D) }\end{array}$ & $\begin{array}{l}\text { Set of all ASM rules to interprete } \\
\text { all nodes/states in a SBD(iagram) } \\
\text { D for a given subj (set of all } B E \text { - } \\
H A V I O R(\text { subj;node)) }\end{array}$ & Execution concept \\
\hline $\begin{array}{l}\text { PER- } \\
\text { FORM(subj ; } \\
\text { service(state); } \\
\text { state) }\end{array}$ & $\begin{array}{l}\text { The main Perform ASM } \\
\text { Rule/Method that prompts a } \\
\text { PASS interpreter to execute func- } \\
\text { tions defined for states }\end{array}$ & $\begin{array}{l}\text { State hasFunctionSpecifica- } \\
\text { tion FunctionSpecification } \\
\text { Specialized in: } \\
\text { DoFunction and. } \\
\text { CommunicationActs with } \\
\text { ReceiveFunction } \\
\text { SendFunction } \\
\text { There exist a few default activities: } \\
\text { DefaultFunctionDo1_En- } \\
\text { voironmentChoice } \\
\text { DefaultFunctionDo2_Auto- } \\
\text { maticEvaluation }\end{array}$ \\
\hline $\begin{array}{l}\text { PER- } \\
\text { FORM(subj;Co- } \\
\text { mAct; state })\end{array}$ & $\begin{array}{l}\text { ASM-Rule specifying the execu- } \\
\text { tion of a Communication act in } \\
\text { an according state) }\end{array}$ & $\begin{array}{l}\text { CommunicationActs with } \\
\text { ReceiveFunction } \\
\text { SendFunction } \\
\text { DefaultFunctionReceive1_En- } \\
\text { vironmentChoice } \\
\text { DefaultFunctionReceive2_Au- } \\
\text { toReceiveEarliest } \\
\text { DefaultFunctionSend }\end{array}$ \\
\hline
\end{tabular}

There are some prototypes of modeling tools which follow the standard ontology of PASS and a prototype of a workflow engine which interprets the standard ontology [18].

\section{References}

1. Fleischmann, A. (1994). Distributed systems: Software design and implementation. Berlin: Springer.

2. Meyer, N., Thomas, F., Radmayr, M., Blei, D., \& Fleischmann, A. (2010). Dynamic creation and execution of cross organisational business processes- The jCPEX! approach. In S-BPMONE 2010; CCIS 138. Heidelberg: Springer.

3. Flowgorithm. Flowgorithm, September 2019. [Online]. Last accessed September 2019, from http://www.flowgorithm.org/

4. Myers, B. A. (1986). Visual programming, programming by example, and program visualization: A taxonomy. ACM SIGCHI Bulletin, 17(4), 59-66. 
5. Nüüttgens, M., \& Mendling, J. (2004). Transformation of ARIS XE “ARIS” markup language to EPML. Proceedings of the 3rd GI Workshop on Event-Driven Process Chains (EPK 2004), Luxembourg.

6. Kopp, O. (2005). Abbildung von EPKs nach BPEL anhand des Prozessmodellierungswerkzeugs Nautilus, Stuttgart: Diploma Thesis, University of Stuttgart.

7. Wikipedia [Online]. Last accessed October 2019, from https://en.wikipedia.org/wiki/ List_of_Unified_Modeling_Language_tools

8. Backhauß, S. (2016). Code generation for UML XE "UML" activity diagrams in real-time system. Hamburg: Master Thesis; Hamburg University of Technology.

9. Dirndorfer, M., Fischer, H., \& Sneed, S. (2013). Case study on the interoperability of business process management software. BPM ONE-Running Processes, CCIS 360. Springer.

10. Kossak, F. et al.. (2014). A rigorous semantics for BPMN 2.0 process diagrams. Springer.

11. Börger, E. (2003). Abstract state machines: A method for high-level system design and analysis. Heidelberg: Springer.

12. Elstermann, M. (2017). Proposal for using semantic technologies as a means to store and exchange subject-oriented process models. Darmstadt, Germany.

13. Geiger, M., Harrer, S., \& Wirtz, G. (2018). BPMN 2.0: The state of support and implementation. Future Generation Computer Systems. pp. 250-262.

14. McGuiness, D. L., \& van Harmelen F. (2004). OWL XE "OWL" web ontology language overview. W3C recommendation, $10(10)$.

15. Elstermann, M., \& Krenn, F. (2018). The semantic exchange standard for subject-oriented process models. Linz: ACM.

16. Börger, E., \& Raschke, A. (2018). Modeling companion for software practitioners. Springer.

17. Börger, E. (2012). A precise description of the S-BPM modeling method. In Subject-oriented business process management. Heidelberg: Springer.

18. Fleischmann, A., Borgert, S., Krenn, F., Singer, R., \& Elstermann, M. (2018). An overview to S-BPM oriented tool suites. S-BPM-ONE 2018. ACM Digital Library

Open Access This chapter is licensed under the terms of the Creative Commons Attribution 4.0 International License (http://creativecommons.org/licenses/by/4.0/), which permits use, sharing, adaptation, distribution and reproduction in any medium or format, as long as you give appropriate credit to the original author(s) and the source, provide a link to the Creative Commons licence and indicate if changes were made.

The images or other third party material in this chapter are included in the chapter's Creative Commons licence, unless indicated otherwise in a credit line to the material. If material is not included in the chapter's Creative Commons licence and your intended use is not permitted by statutory regulation or exceeds the permitted use, you will need to obtain permission directly from the copyright holder. 